\title{
CECY: California's collaborative approach to increasing employment of youth and young adults with intellectual disabilities
}

\author{
Olivia Raynor $^{\mathrm{a}, *}$, Katharine Hayward ${ }^{\mathrm{a}}$ and Kathleen Rice ${ }^{\mathrm{b}}$ \\ ${ }^{\mathrm{a}}$ Tarjan Center/University of California, Los Angeles, CA, USA \\ ${ }^{\mathrm{b}}$ K L Rice Consulting, Oakland, CA, USA
}

Revised/Accepted April 2017

\begin{abstract}
.
BACKGROUND: Collaboratives have been shown to be effective at addressing complex problems and powerful drivers of systems change (Chrislip, 2002). The intractable problem of low employment for youth and young adults (YYA) with intellectual and developmental disabilities (IDD) cannot be solved by one agency alone.

OBJECTIVE: This article describes the California Employment Consortium for Youth with IDD ("CECY”) and its impact in California.

CONCLUSION: The California Employment Consortium for Youth with IDD was an alliance of 45 representatives from 25 local and state agencies, associations, organizations, families, and self-advocates committed to building capacity and partnerships among state and local agencies and stakeholders to foster meaningful, sustainable changes in the systems that support YYA with IDD to achieve employment. Guiding this work were two models for change, the High Performing States Framework, that identifies effective elements for employment systems change; and Collaborative Leadership, a process to constructively engage diverse stakeholders in dialogue, mutual learning, shared responsibility, and action. This article describes the organization, administration, strategic actions, outcomes, and lessons learned from implementing a state level systems change project.
\end{abstract}

Keywords: Developmental disabilities, collaborative leadership, employment, systems change

\section{Introduction}

For decades throughout the nation, the employment for youth and young adults (YYA) with intellectual and other developmental disabilities (IDD) has been intractably low. In 2011, California (CA) was one of 8 states to successfully compete for a Partnerships in Employment Systems Change

\footnotetext{
*Address for correspondence: Olivia Raynor, Ph.D., Tarjan Center at UCLA, 760 Westwood Plaza, Ste 58-217, Los Angeles, CA 90095-1759, USA. Tel.: +1 310794 1141; E-mail: oraynor@mednet.ucla.edu.
}

grant from the Administration on Intellectual and Developmental Disabilities, U.S. Department of Health and Human Services. An underlying assumption of this initiative was that a shifting and realignment of policies that influence the structures and operations of states' surrounding employment systems needed to occur for significant improvements in the employment of people with disabilities (Foster-Fishman, Nowell, \& Yang 2007). To this end, the California Employment Consortium for Youth with Intellectual and Developmental Disabilities ("CECY") was established with the mission to 
stimulate policy change and build capacity in CA state systems and local communities to increase the number of individuals with IDD in competitive integrated employment (CIE). CECY's goals were to: 1) Strengthen interagency collaborations and practices between and among local and state agencies to increase opportunities for CIE; 2) Enhance the understanding of YYA, family members, and professionals of the effective practices and supports for YYA with IDD to work in CIE; and 3) Effect policy change at the state and local level aimed at increasing the employment of YYA with IDD. This article describes CECY and its use of the High Performing States Framework (Hall, Butterworth, Winsor, Gilmore, \& Metzel, 2007) and Collaborative Leadership (Chrislip \& Larson, 1994) approach to build capacity and partnerships among state agencies and stakeholders to foster meaningful, sustainable changes in the systems that support YYA with IDD.

\section{Background}

\subsection{California context}

For nearly 50 years, CA's Lanterman Developmental Disabilities Act ("Act") has entitled qualified individuals with IDD to an array of services and supports to live and participate in their own communities. The Act is codified in the California Welfare and Institutions Code (Welfare and Institutions Code Sections 4500 et seq.). Under the Act, the Department of Developmental Services (DDS) contracts with 21 independent community based non-profit regional centers throughout CA to provide service coordination and a variety of community services and supports that meet the needs and choices of individuals with IDD (The Scan Foundation, 2013; Lanterman Developmental Disabilities Act and Related Laws, 2017).

In 2016, the regional center system served approximately 300,000 individuals with IDD, of which 85,921 received employment (work activity, group or supported employment) or day services. The majority $(77 \%)$ attended day programs that typically do not provide or provide limited access to employment opportunities. Few regional center clients $(5 \%)$ received individual employment services for CIE. Sixteen percent of regional center clients, 16-64 years old, had earned income although most earned subminimum wages $(60 \%)$. The average annual earnings of the regional center clients were \$7,248 (Regional Center Oversight Dashboard, 2017;
Developmental Services Task Force Workgroup on Housing and Employment, 2016). ${ }^{1}$

It took 6 years and multiple attempts for the state to adopt an Employment First Policy in 2013. According to state law, "... It is the policy of the state that opportunities for integrated competitive employment shall be given the highest priority for working age individuals with developmental disabilities, regardless of the severity of their disabilities. This policy shall be known as the Employment First Policy" (Welfare and Institutions Code $\S 4869$ (a), 2013). In addition, the law provided a definition and measurement for "integrated competitive employment" (competitive, self-employment, and microenterprise). It also required employment be the first option for working age adults considered by regional center planning teams. Individuals 16 and older are to be informed of the policy and opportunities related to achieving integrated competitive employment, including needed supports and postsecondary education.

However, it was only very recently that CIE became a measurable outcome rather than simply a provided service. In 2016, after decades of service cuts, funding reductions and frozen provider rates in the DD system, new funding was made available for employment services, a paid internship program, and incentive payments for placement, and retention in CIE (Welfare and Institutions Code $\S 4870,2016$ ).

In addition to DDS, the CA Departments of Education (CDE) and Rehabilitation (DOR) also have responsibilities toward the preparation, placement and long term employment supports for individuals with IDD. In 2014, the 3 agencies, in collaboration with Disability Rights California (DRC), signed a historic agreement to establish and implement an interagency plan, the California Competitive Integrated Employment Blueprint for Change ("Blueprint"). The primary goal of the Blueprint is to increase the number of individuals with IDD who achieve CIE using existing resources through: (1) collaboration and coordination between the three agencies; and for individuals with IDD to have, (2) increased opportunities to prepare for and participate in the workforce development system and (3) to make informed choices, prepare for and transition to CIE. The plan and its implementation are

\footnotetext{
${ }^{1}$ The average earnings was calculated from the wages reported by employers for all regional center clients. This included clients who had or had not receive employment services. The data excluded individuals who were self employed or independent contractors.
} 
consistent with other federal laws and mandates for education and employment including the Individuals with Disabilities Education Act, the Workforce Innovation and Opportunity Act and the Home and Community Based Services Settings Rule (California Department of Education, California Department of Rehabilitation, California Department of Developmental Services, 2016). The Blueprint establishes for the first time benchmarks and expectations for CIE, delineates roles and responsibilities for each agency, and outlines how individuals with IDD will be informed of the opportunities available for CIE. The Blueprint was finalized in May 2017 and released in English and six threshold languages (Spanish, Chinese, Armenian, Russian, Vietnamese, and Tagalog).

\section{Organizational approach}

This section describes the two frameworks that helped lay the groundwork for CECY's focus and process for building capacity for change.

\subsection{High Performing States Framework (HPS)}

There are a myriad of factors that may impact the employment of YYA with IDD. The HPS Framework offers an understanding of the effective strategies implemented in states that had achieved high rates of integrated employment and/or high growth in CIE. It is based on systems thinking which views the context (employment system), catalysts (values, leadership, and key stakeholders), strategies implemented, and outcomes as multidirectional, interconnected, and interdependent. Strategies include flexibility and innovations in: 1) policy and clarity of goals; 2) financing; 3) training and technical assistance; 4) service innovation; and 5) accountability and collection of outcome data. Within the HPS model, the catalysts and context (stakeholders, values, goals, and commitment) facilitate the implementation of systemic strategies that lead to successful goal achievement in employment. Given the complexity of systems transformation, the HPS model was used to assist the consortium to create a shared understanding of the key elements of high performing state employment systems. The framework served as a practical guide toward establishing priorities. We also used the HPS framework to categorize strategies implemented by CECY members as indicators of progress.

\subsection{CECY process: Collaborative leadership}

A complex and multifaceted issue such as employment cannot be addressed by single leaders or agencies alone, and requires leadership that cuts across organizational boundaries. CECY adopted the approach of collaborative leadership to break down traditional silos, foster cross-agency activities, and create an environment that fosters creativity and innovation. The central premise of collaborative leadership is "if you bring the appropriate people together in constructive ways, with good information, they will create authentic visions and strategies for accessing the shared concerns of the organization or community" (Chrislip \& Larson, 1994, p. 4). Collaborative leaders need to be effective in building relationships and trust; facilitating complex processes; and working across cultural, ideological, social, and organizational differences. They need to be skillful in: understanding each other's motivations for collaboration; making complex situations comprehensible and workable; helping groups develop shared visions and actionable plans; working with and through conflict; assessing the environment for change and determining who to partner with; sharing and redistributing power; drawing out the passions of the members; sharing credit; having patience, tenacity, and empathy; holding difficult conversations and coalition building (Chrislip \& Larson, 1994; Chrislip, 2002; Asher \& Cameron, 2013). Some leaders are present at the beginning of a collaborative; others emerge or develop over time. These leaders also serve as vital link between the collaborative and stakeholders, including formal decision making bodies and those responsible for implementation within their own organizations, agencies, councils or programs.

\section{Components of the consortium}

\subsection{Membership}

CECY was a collaboration of 45 representatives from 25 local and state agencies, associations, organizations, families, and self-advocates with responsibilities for the education, preparation, support, and employment of YYA with IDD. Organizations and agencies represented included the Departments of Rehabilitation, Education, and Developmental Services, the State Council on Developmental Disabilities, Disability Rights California, the Tarjan Center at UCLA, a University Center for Excellence 
in Developmental Disabilities, Special Education Local Plan Areas (SELPA), California Transition Alliance, The Arc of California, and the California Foundation for Independent Living. The majority of members had their own professional networks including councils, committees, parent groups, selfadvocacy networks, or other associations that could also serve as a catalyst for change. In addition, some CECY members were also leaders from other important state initiatives designed for the improvement of employment outcomes of individuals with IDD, including CaPROMISE (Promoting Readiness of Minors in Supplemental Security Income) and California's Disability Employment Initiative (DEI).

\subsection{Workgroups, youth advisory committee and local employment collaborative teams}

CECY's workgroups were established based on a priority setting process conducted by the Consortium. They were informed by identified barriers to CIE and strategies from the HPS. We clustered activities into five workgroups, who were named by their members: policy ("The Policy Change Artists"), best practices ("America's Next Top Models"), state data and performance indicators ("Data Nerds"), outreach and communication ("the Outreachers"), and resource development ("the Unbroken Chain"). Table 1 shows the workgroups and their corresponding objectives.

CECY members joined one or more groups of their choosing. Each workgroup was co-chaired by "LEADS" who were each from different representative agencies or organizations. CECY members regularly reviewed and updated priorities, timelines, accomplishments, and deliverables of the workgroups.

Often, members from one workgroup participated in other workgroups when the issues being addressed were related. For example, the "Policy Change Artists" and "Data Nerds" worked together to develop policy recommendations for data sharing to ascertain the number of individuals with IDD who were employed and receiving specific services. The "Outreachers" and "Unbroken Chain" also had a reciprocal relationship, and were often in communication sharing their findings and resource compilation. By the 4th and 5th years, these two workgroups were combined.

CECY established a Youth Advisory Committee (YAC) in October 2012. YAC formally met for one year as a stand-alone advisory committee to CECY. Members provided insight on the priorities and perspectives of youth with disabilities, and offered substantive input on CECY related products and priorities. Over the last 5 years, 5 YAC members attended quarterly meetings and 1 member regularly participated in the policy workgroup. Facilitation for the YAC was provided by a young professional with a disability with extensive experience in youth leadership among youth with disabilities. YAC members provided direct input into the work of CECY, and insight into both the aspirations of YAA with IDD and systemic barriers encountered by them. These youths were also encouraged to take actions that equipped them to achieve CIE; several have successfully obtained internships, employment, or are in the process of attending college.

A final component of CECY was the Local Employment Collaborative Teams (LECTS). CECY conducted a call for local, successful, and collaborative practices to gain further understanding of the complex interdependencies between policy, practice, and community resources in the achievement of CIE for YYA with IDD. In January 2012, seven programs were selected for their successful strategies, as well as their geographic and contextual differences, to partner with CECY's state activities and policy work. Each program was awarded a total of $\$ 30,000$ over 2 years to document their practices. The selected agencies and organizations represented 4 secondary schools, 1 college, and 2 providers that each had a unique focus: job supports with effective

Table 1

CECY workgroups and objectives

\begin{tabular}{ll}
\hline Workgroup & Objectives \\
\hline Policy Change Artists & $\begin{array}{c}\text { To assess current policies and practices within and across agencies and make recommendations to } \\
\text { advance CIE. } \\
\text { To create a go-to website for professionals and families that displays employment and related data } \\
\text { from various sources in a user-friendly way. }\end{array}$ \\
$\begin{array}{l}\text { To better understand the expectations and need for resources and information by families and } \\
\text { teachers in transition to postsecondary education and/or employment. }\end{array}$ \\
$\begin{array}{l}\text { To uncover and disseminate effective practices from diverse local communities that demonstrate } \\
\text { success at achieving CIE. } \\
\text { To create a resource tool for transition from school to work for YYA with IDD. }\end{array}$
\end{tabular}


job matching, occupational certificates, community partnerships, use of technology for job searching and applications, parent and family involvement in job placement, benefits planning training, interagency collaboration, and sequenced funding and braided services. By the end of the second year, all of the LECTs reported employment rates above the California rate of $12-13 \%$; the percentage of LECT participants employed in integrated settings ranged from $16 \%$ to $100 \%$.

Each LECT also served as the lead convener for a local Community Conversation event. A Community Conversation is an evidence-based method (adapted from the World Café format) for creatively engaging diverse individuals in collaborative dialogue to generate fresh ideas, solutions, and action steps around improving an issue (Swedeen, Cooney, Moss, \& Carter, 2011).

CECY staff provided the technical assistance, training, facilitation, and evaluation for planning and executing these events. Each community was encouraged to outreach to employers with and without experience in working with/hiring individuals with disabilities. Four hundred thirty-one community members, including over 80 employers, participated in the events; including representatives from chamber of commerce, higher education, local business, service organizations, civic groups, as well as elected/local officials, religious leaders, families, and YYA with IDD.

\subsection{Administration}

The overall management of CECY was the responsibility of the Tarjan Center at UCLA and staffed by its Director, Communications and Program Manager, and Project Evaluator. The Center provided the administration, leadership, and coordination for CECY and its operations; developed meeting agendas/desired outcomes; supported all workgroups; facilitated information sharing among members; developed an internal CECY member website and weekly CECY E-News; finalized and disseminated accessible products; and managed logistics for virtual and in-person meetings. Five subject matter consultants (including previous state or local agency directors) were directly involved or co-led a workgroup. Additional subject matter consultation in school-to-work transition was received through Vision Quest, a 10-month technical assistance grant CECY received in 2014 from the Office of Disability Employment Policy, U.S. Department of Labor.
AIDD also provided technical assistance to each of the awarded Partnerships in Employment System's change grantees through the Institute for Community Inclusion and National Association of State Directors of Developmental Disabilities Services. Their staff provided a national context, content expertise, and sharing of information across projects.

CECY held monthly webinar meetings and quarterly all day in-person meetings. Meetings were held in the state capitol, Sacramento, to make attendance of state agency leadership possible. Meeting space was provided by state agencies or the local regional center.

The co-chairs of the workgroups, the "LEADS," also met monthly to review the progress of their workgroups and products and to discuss their priorities, activities, and needs. CECY utilized a professional facilitator for our quarterly meetings who guided the process in accordance with the principles of Collaborative Leadership. The desired outcomes and content for each meeting was developed by a leadership team, including the director and "LEADS" of each of the workgroups. Quarterly all day meetings were highly participatory, using small and large group format for processing information and making decisions. Commonly, the morning activities were dedicated to agency updates, topical trainings, and information sharing. The afternoons often structured dedicated time for workgroup meetings. In years 4 and 5, CECY received regular updates and provided consultation toward the development of the Blueprint at each meeting. For example, ideas and recommendations were provided toward: a career portfolio; creating a Memorandum of Understanding (MOU) between local agencies for CIE; and strategies for effective partnerships with local America Job Centers.

The Consortium and its process was evaluated through several methods including Tarjan Center developed in-person meeting evaluations, online indepth surveys on a quarterly/biannual basis, and an annual Partnership Self-Assessment Tool (2002). Evaluations were used to establish priorities, professional development needs, and assess barriers to implementation. CECY was required to submit biannual evaluation data to an external evaluator of all the Partnerships in Employment projects.

\section{Strategic actions, activities and outcomes}

CECY developed a set of five strategic actions to guide and develop activities to achieve the goals and objectives of CECY work groups. These actions and 
their corresponding activities build heavily upon the HPS Framework and CA's unique context to support a systemic shift toward CIE.

Strengthening ties within CECY and its partnering agencies, families, and YYA with IDD. This refers to the work within the Consortium to develop leadership, foster innovation, and ensure individual and agency commitment. The meetings were designed to encourage relationship building, sharing of knowledge, problem solving of issues, cross-agency communication and collaboration, and support for implementation of CIE within member organizations and local communities.

Impacting public policies and practices that support CIE. This strategic action addressed CECY's focus on removing policy and practice barriers as well as promoting systems change. This included conducting reviews and analyses of current state policies, administrative and funding structures and services provided by the three primary state agencies, DDS, CDE, and DOR. These reviews formed the basis for policy briefs and other informational materials intended for policy makers and professionals. CECY's policy efforts were directed towards the successful passage of Employment First Policy and Self Determination law, and the full funding of the DD system.

The Employment First Policy represented an important philosophical shift for California and a clear message that individuals with IDD have the right to make an informed choice about working. While this policy was an important starting point, it did not require fundamental changes to the regional center system to ensure its implementation or outcomes. Such change would require an examination of all facets of the system from the services provided, funding structures, provider capacity, and data management. CECY provided invaluable assistance to the state through its systemic review, recommended strategies, documentation of successful practices and successful model of cross agency collaboration.

On a local level, CECY worked to advance the implementation of Employment First by identifying regional examples of successful practices. CECY's LECTS served as regional exemplars in the preparation, support and achievement of CIE by people with IDD. Individual regional centers also began to adopt their own Employment First Policy. The Regional Center of Orange County (RCOC), represented on CECY by its Director and leadership staff, were early adopters of a local Employment First Policy. CECY provided RCOC technical assistance regarding shutting the door to segregated work, data collection, and preparing and educating the community for CIE.

It was not until the agreement to establish the Blueprint that the state agencies began planning for the coordination and structural changes needed in the system to achieve the vision of the Employment First Policy. There was a dynamic interplay between the resources and expertise of CECY and the development of the Blueprint as the individuals drafting the Blueprint were also CECY members. CECY was uniquely positioned to be useful for addressing the myriad of issues associated with moving Employment First policy into practice.

Raising expectations for CIE and expanding youth and family involvement. CECY focused on raising the aspirations and expectations of families, providers, professionals, employers, and other community members for CIE. Parents and educators were surveyed to understand their post-school expectations for postsecondary education and employment for their youths with IDD. Families, individuals with IDD, and professionals wanted and benefitted from stories of success and resources to envision and support a future for YYA that included CIE. The survey information was used to inform a CECY written guide, "I Want to Work, I Know I Can" for teachers and families to help youth set personal goals with helpful resources for their path to employment (Sawyer, n.d.).

Establishing cross-system accountability and indicators of progress. Members focused on identifying relevant data and information to establish a baseline for employment of individuals with IDD across state systems and agencies. CECY created the Employment Data Dashboard, an online visual display of multi-agency data for easy access and tracking of state progress in CIE. Data is a powerful tool for advocacy, and members utilized the Data Dashboard to show the current low participation rate and employment of YYA with IDD. Going forward, the Data Dashboard will be used to track the effectiveness of the Blueprint implementation strategies and employment outcomes for individuals with IDD.

On a quarterly basis, individual and agency members reported actions that they had taken toward the implementation of policy and practice related to CIE. For example, "Drafted an MOU with the Franchise Tax Board for data sharing", "Hosted a Breakfast for Champions of top 14 local employers", and "Revised work services monitoring tool related to implementation of Employment First." Members were asked to categorize their strategies by the elements of 
HPS and CECY's strategic actions. Strategies were discussed among members and used as indicators of progress across the various member agencies, organizations, etc. These practices were posted by members on a wall at meetings and shared in the form of a searchable directory.

Spreading what works. This refers to the capacity building and information sharing aspects of CECY's work used for families, professionals, providers, and YYA with IDD. Multiple methods for dissemination were used including presentations, webinars, websites, policy and informational briefs, resource guides, and weekly CECY E-news. CECY organized two 'employment' strands at the bi-annual CDE sponsored "Bridge to the Future" Transition Institute attended by over 1,000 transition specialists, rehabilitation counselors, families, and youth with IDD. Table 2 illustrates the range of activities and outcomes of the workgroups toward the accomplishment of CECY's goals and objectives.

\section{Planning for sustainability}

Serious consideration was given to ensure that the work of CECY was about more than a time limited 5-year grant period. Planning for sustainability was a part of the discussions from the start. The emphasis was on planning for how members would integrate CECY's work with that of their local or state agency, organization, or council. For example, a written agreement was established between CECY, DDS, and California State Council on Developmental Disabiities (SCDD) to continue the development and hosting of the Employment Data Dashboard on the SCDD website. The Tarjan Center will continue to support the public CECY website and its dissemination of products, including producing the weekly CECY E-News. The shared vision, cross agency understanding, deep familiarity with one another's work and priorities, and CECY's resources will continue to serve the state well as it moves into the implementation of the Blueprint. The Employment Development Division, under its DEI initiative, is providing support for the Tarjan Center to host CECY quarterly webinars through 2018.

\section{Lessons learned}

\subsection{Federal investment drove system change}

CECY identified a workable set of state and local strategies for policy and practice for the employment of youth with IDD including a visual display of data, outcome funding, successful practices, crossagency professional development, and community engagement. CECY members made important incremental changes within their own work and that of their agencies/organizations. Even though CECY did not have the singular authority to make the wide scale and long-term systemic change that is now planned for in the Blueprint, the Blueprint workgroup leaders were highly engaged CECY members. Through CECY, they developed a comprehensive understanding of each other's work that they considered a catalyst for change and served as foundation to the Blueprint and its future implementation (D. Curtright, personal communication, September 21, 2016).

The CECY model was also adopted at the local level. CECY served as an example to other teams, workgroups, and consortia in the state. For example, a California Special Education Local Plan Area (SELPA) Director and CECY member established a local transition group modelled after CECY.

\subsection{Creating a neutral space for dialogue, collaboration, and change}

The Tarjan Center, a university based, independent, non-governmental agency provided the administrative structure and program support for CECY. An expert and impartial facilitator was utilized for the quarterly meetings to create a welcoming environment and neutral space conducive to relationship building, discussing sensitive topics, and cultivating consensus. Meetings were not bound by strict governmental procedures or any single agency agenda; this allowed members to freely express and work through challenges such as competing priorities, conflicting values, issues, or concerns. For example, the use of subminimum wage and segregated services (sheltered work) was a contentious issue for some CECY members. Over a series of meetings, the differing viewpoints over the use of subminimum wage evolved into one about preparing for the implementation of the Employment First Policy and new federal laws and mandates prohibiting its use. Over the course of two years, the Regional Center of Orange County (RCOC), a CECY member, served as a case study for how local agencies institute an Employment First policy. RCOC no longer allows new entries into sheltered work and is now a model for the 20 other regional centers across the state. 

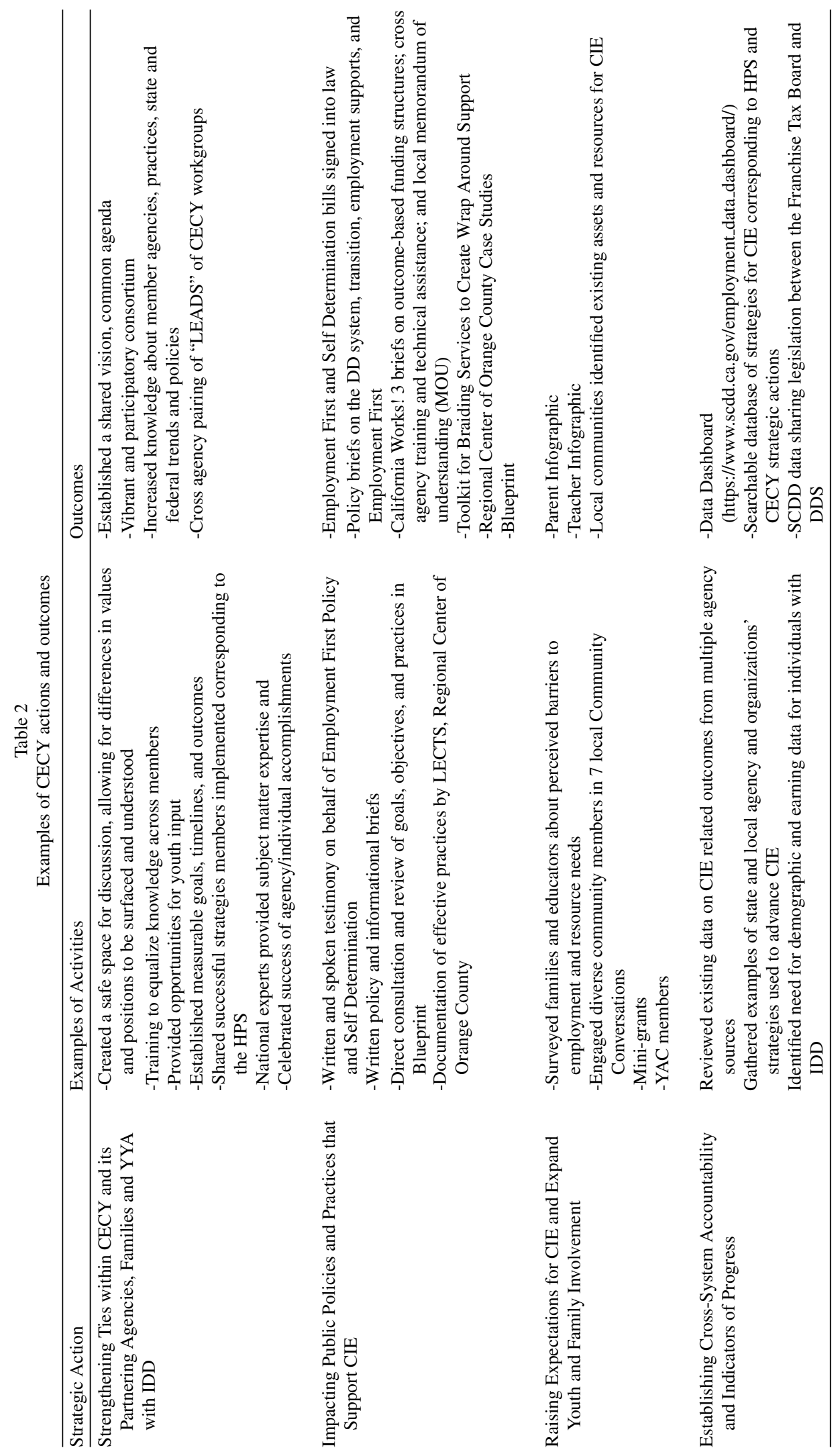


\subsection{Partnerships are essential}

Partnership is at the core of success of this project. CECY members built relationships that led to formal and informal partnerships and created meaningful alliances across agencies, organizations, and other stakeholders with a shared commitment for CIE. CECY members were individually empowered to serve as a resource to their own agencies/organizations and to one another; thereby gaining knowledge, confidence, important linkages and the capacity to avert potential misunderstandings and conflict. Often, members consulted with each other outside of CECY meetings, utilizing one another's expertise to advance CIE.

\subsection{Local community members are part of the solution}

CECY invited community members outside of governmental agencies to be part of the solution toward increasing employment for YYA with IDD. CECY's experience with the 7 Community Conversations showed that a broad constituency of community members from businesses, local and state government, service organizations, and schools and colleges cared about the issue. Community Conversation attendees were willing to contribute their skills and resources, as well as identify existing opportunities for employment in their local communities. Tapping into non-traditional local partnerships may facilitate networking opportunities and open new doors for employment.

\subsection{Share and celebrate successes}

Systems change takes a long time to achieve. Thus, it was important to celebrate and acknowledge incremental change and how each small or large accomplishment sustained forward momentum. It was also important to allow opportunities for individuals and agencies to share and get feedback on new developments, success stories, and/or changes underway.

\section{Concluding remarks}

The federal investment in California set the state on a trajectory toward long-term systemic change towards CIE. Through CECY's work, members developed a deep understanding of the policies, practices and administrative structures that inhibited and/or supported CIE - a process that could have taken the state a decade to achieve without federal investment. Not only did members develop knowledge and expertise, but also the capacity to put that knowledge into action. The time and investment made yielded strong progress toward laying the foundation for the larger transformation of the system yet to come through the implementation of the Blueprint. As this work within the state continues, it has the potential to build a responsive workforce system, influence, and reach significant scale in increasing the employment of YYA with IDD.

\section{Acknowledgments}

Funding Note: Support for the California Employment Consortium for Youth and Young Adults with Intellectual and Other Developmental Disabilities came from a Project of National Significance Partnerships in Employment Systems Change Grant funded by the Administration on Intellectual and Developmental Disabilities, Grant \#90D0N0284 (10/01/11-9-30/17).

\section{Conflict of interest}

None to report.

\section{References}

Archer, D., \& Cameron, A. (2013). Collaborative leadership: Building relationships, handling conflict, sharing control. New York, NY: Routledge.

California Department of Education, California Department of Rehabilitation, California Department of Developmental Services. (2016). Employing individuals with intellectual disabilities and developmental disabilities in California, "Real Work for Real Pay in the Real World." Retrieved From http://www.chhs.ca.gov/Pages/Competitive-IntegratedEmployment-(CIE).aspx

Chrislip, D. D. (2002). The collaborative leadership fieldbook: A guide for citizens and civic ceaders. San Francisco, CA: Jossey-Bass.

Chrislip, D. D., \& Larson, C. E. (1994). Collaborative leadership: How citizens and civic leaders can make a difference. San Francisco, CA: Jossey-Bass.

Curtright, D. Personal Communication, September 21, 2016.

Data USA Los Angeles County (n.d.). Retrieved from https:// datausa.io/profile/geo/los-angeles-county-ca/

Developmental Services Task Force Workgroup on Housing and Employment, November 1. 2016.

Foster-Fishman, P. G., Nowell, B., \& Yang, H. (2007). Putting the system back into systems changes: A framework for 
understanding and changing organizational and community systems. American Journal of Community Psychology, 39, 197-215.

Hall, A. C., Butterworth, J., Winsor, J., Gilmore, D., \& Metzel, D. (2007). Pushing the employment agenda: Case study research of high performing states in integrated employment. Intellectual and Developmental Disabilities, 45(3), 182-198.

Lanterman Developmental Disabilities Servcies Act and Related Laws. (2017). Retrieved from http://www.dds.ca.gov/statutes/ Statutes_Home.cfm

Partnership Self-assessment Tool-Questionnaire (2002). Center for the Advancement of Collaborative Strategies in Health, Retrieved from http://atrium.lib.uoguelph.ca/xmlui/bi tstream/handle/10214/3129/Partnership_Self-Assessment_To ol-Questionnaire_complete.pdf?sequence $=1 \&$ is Allowed=y

Regional Center Oversight Dashboard. (2017, January 19). Retrieved from http://www.dds.ca.gov/RCOversight/Index. $\mathrm{cfm}$
Sawyer, S. (n.d.). I Can Work! I Know I Can! Transition Alliance and CECY. Retrieved from http://www.catransitiona lliance. .org/content.aspx?id=1561

Swedeen, B., Cooney, M., Moss, C., \& Carter, E. W. (2011). Launching inclusive efforts through community conversations. Retrieved from http://www.waisman.wisc.edu/cedd/ pdfs/products/community/LaunchingInclusiveEfforts.pdf

The SCAN Foundation. (2013, June). Long term fundamentals. California's developmental disabilities service system, No.12. Retrieved from http://www.thescanfoundation. org/californias-developmental-disabilities-service-system

Welfare and Institutions Code Sections 4500 et seq.

Welfare and Institutions Code $\S$ Sect. 4869 (a) (2013).

Welfare and Institutions Code $\S 4870$ (2016). 